\title{
The Effects of Certain Gasotransmitters Inhibition on Homocysteine Acutely Induced Changes on Rat Cardiac Acetylcholinesterase Activity
}

\author{
Marko Djuric ${ }^{1}$, Slavica Mutavdzin², Dragana Loncar-Stojiljkovic ${ }^{3}$, Sanja Kostic ${ }^{4}$, \\ Mirjana B. Colovic ${ }^{5}$, Danijela Krstic ${ }^{6}$, Vladimir Zivkovic ${ }^{7}$, Vladimir Jakovljevic ${ }^{7}$, \\ and Dragan M. Djuric ${ }^{2}$
}

\section{ABSTRACT}

Background/Aim: Hyperhomocysteinaemia is linked to higher level of acetylcholinesterase (AChE) in brain, but there is insufficient information on influence of homocysteine (Hcy) and gasotransmitters on cardiac AChE. Thus, the aim of this study was to evaluate the influence of certain gasotransmitter inhibitors in Hcy-induced changes on rat cardiac AChE activity.

Methods: Research was performed on 72 male Wistar albino rats distributed into 6 groups: 1) Control group - saline ( $1 \mathrm{ml} 0.9 \% \mathrm{NaCl}$ ip); 2) DL-Hcy ( $8 \mathrm{mmol} / \mathrm{kg}$ ip DL homocysteine (DL-Hcy); 3) L-NAME (10 mg/kg ip $\mathrm{N}^{\omega}$-Nitro-L-arginine methyl ester (L-NAME), inhibitor of NO production); 4) DL-PAG (50 mg/kg ip DL-propargylglycine (DL-PAG), inhibitor of H2S production); 5) DL-Hcy+L-NAME (8 mmol/ $\mathrm{kg}$ ip DL-Hcy + $10 \mathrm{mg} / \mathrm{kg}$ ip L-NAME); and 6) DL-Hcy+DL-PAG (8 mmol/ $\mathrm{kg}$ ip DL-Hcy $+50 \mathrm{mg} / \mathrm{kg}$ ip DL-PAG). All tested substances were administered in a single dose, intraperitoneally, 60 minutes before animals' sacrifice. AChE activity was measured in the rats' cardiac tissue homogenate.

Results: Administration of Hcy and L-NAME induced significant decrease in AChE activity compared with control condition. Administration of DL-PAG, DL-Hcy+LNAME and DL-Hcy+DL-PAG did not change AChE activity compared with the control group.

Conclusion: The effects of acute Hcy administration on the cardiac AChE activity are partially mediated via interaction with tested gasotransmitters.

Key words: acetylcholinesterase, heart, homocysteine, inhibition.

\section{INTRODUCTION}

Hyperhomocysteinaemia is an independent predictor of different diseases such as, cardiovascular and cerebrovascular diseases, neurodegeneration and cancer. ${ }^{1}$ Increased blood homocysteine (Hcy) level independently predicted all-cause and cardiovascular mortality in the general and especially in the older population, ${ }^{2}$ and it has been recognised as a risk factor for cardiovascu-
(1) Department of Anaesthesiology, Reanimatology and Intensive Care Medicine University Clinical Hospital Center "D Dragisa Misovic - Dedinje", Belgrade.

(2) Institute of Medical Physiology "Richard Burian", Faculty of Medicine, University of Belgrade, Belgrade.

(3) Department of Anaesthesiology and Critical Care, Institute for Cardiovascular Diseases "Dedinje", Belgrade, Serbia.

(4) Faculty of Medicine, University of Belgrade, Belgrade.

(5) Department of Physical Chemistry Vinča Institute of Nuclear Sciences, University of Belgrade, Belgrade.

(6) Institute of Chemistry in Medicine "Prof. Dr Petar Matavulj", Faculty of Medicine, University of Belgrade, Belgrade.

(7) Department of Physiology, Faculty of Medical Sciences, University of Kragujevac, Kragujevac, Serbia.

\section{Correspondence:}

DRAGAN M. DJURIC

E: drdjuric@eunet.rs

E: dr_djuric@yahoo.com

$\mathrm{T:}+381113607112$

\section{ARTICLE INFO}

Received: 28 July 2019 Revision received: 22 August 2019 Accepted: 4 September 2019 
This may result, probably, in cardiovascular diseases and consequently in an increase of the mortality risk. ${ }^{14}$ It has been reported that after both, acute and chronic Hcy administration in rats, serum BuChE activity was significantly decreased. Antioxidants, such as vitamins E and $\mathrm{C}$, avoided the decrease of this enzyme activity caused by acute Hcy administration, implying that free radicals are responsible for reducing BuChE activity under conditions of acute hyperhomocysteinaemia. ${ }^{14}$ Another study showed that the increased concentration of Hcy in serum decreases the activity of acetylcholinesterase (AChE). ${ }^{15}$ Many tissues, and especially the nerve tissue, are rich in AChE and BuChE. ${ }^{16} \mathrm{BuChE}$ is the most abundant cholinesterase in serum ${ }^{17}$, while AChE is primarily present in membranes of erythrocytes. ${ }^{18} \mathrm{AChE}$ is an enzyme belonging to the group of serine hydrolase with the primary function of hydrolysing neurotransmitter acetylcholine. ${ }^{19}$ It is mainly located at cholinergic brain synapses and neuromuscular junctions. Although less than there, AChE activity could be also very important for functioning of cholinergic system within the heart. ${ }^{20}$ Even if it hydrolyses acetylcholine, it is demonstrated that AChE is also present in hematopoietic tissue and cancer cells that are not innervated by cholinergic system. ${ }^{21}$

Cetrain signaling gaseous molecules or gasotransmitters, such as nitric oxide (NO) and hydrogen sulfide (H2S) participate in effects of Hcy-thiolactone on the coronary circulation and myocardial function. ${ }^{22,23}$ Gasotransmitters have many important roles. They participate in the regulation of inflammation, modulation of mitochondria respiration and activation of antioxidant enzymes and consequently have essential role in oxidative stress regulation, so their cardiac effects are expected and reasonable. ${ }^{24}$ It is demonstrated that S-nitroso-Hcy inhibits hydrogen peroxide production with participation of NO. ${ }^{25} \mathrm{H} 2 \mathrm{~S}$ lowers plasma Hcy level and it scavenge reactive oxygen species and functions as an antioxidant. ${ }^{26,27}$

However, connection between Hcy and certain gasotransmiter effects is still not fully understood. Taken into consideration assumptions referring to existence of AChE within the heart ${ }^{20}$, as well as insufficient data about complex interaction between gasotransimtters and Hcy in the cardiac muscle, researches in order to evaluate the role of gasotransmitters (NO and $\mathrm{H} 2 \mathrm{~S}$ ) on Hcy-induced effects on AChE in rat heart are necessary. Therefore, the aim of this study was to assess the effects of acute administration of DL-Hcy, as well as administration of DL-Hcy together with specific inhibitors of different gasotransmitters, such as $\mathrm{N} \omega$-nitro-L-arginine methyl ester (L-NAME) and DL-propargyl Glycine (DL-PAG) on AChE activity in rat heart tissue.

\section{METHODS}

\section{Physiological Assay and Experimental Protocol}

Experiment was performed on male Wistar albino rats $(\mathrm{n}=72,12$ in each experimental group, 10 weeks old, body weight $250 \pm 30$ g). Experimental animals were housed in pairs with standard food and water available ad libitum. The ambient conditions were strictly controlled (air temperature of $22 \pm 1^{\circ} \mathrm{C}$, relative humidity of $50 \%$, and a cycle of light: dark 12:12 hours, starting light period at $8 \mathrm{AM}$ ). In all experimental groups, tested substances were administered in a single dose, intraperitoneally (ip), 60 minutes before sacrificing of animals. The experimental animals were distributed randomly in one of six groups: 1) Control group - saline (1 $\mathrm{ml} 0.9 \%$ $\mathrm{NaCl} i p, \mathrm{pH} 7.4) ; 2)$ DL-Hcy group ( $8 \mathrm{mmol} / \mathrm{kg}$ ip DL homocysteine); 3) L-NAME group (10 mg/ $\mathrm{kg}$ ip L-NAME as inhibitor of NO production via inhibition of nitric oxide synthase); 4) DL-PAG group ( $50 \mathrm{mg} / \mathrm{kg}$ ip DL-PAG as inhibitor of $\mathrm{H} 2 \mathrm{~S}$ production via inhibition of cystathionine gamma lyase); 5) DL-Hcy+L-NAME group (8 mmol/ $\mathrm{kg}$ ip DL-Hcy + $10 \mathrm{mg} / \mathrm{kg}$ ip L-NAME); 6) DLHcy+DL-PAG group $(8 \mathrm{mmol} / \mathrm{kg}$ ip DL-Hcy + $50 \mathrm{mg} / \mathrm{kg}$ ip DL-PAG).

All experimental procedures were done in agreement with prescribed legislation (EU Directive for the Protection of Vertebrate Animals used for Experimental and other Scientific Purposes 86/609/EES) and the principles of ethics.

\section{Tissue preparation}

Sixty minutes after ip administration of tested substances, the rats were euthanised by decapitation. Whole rats' hearts were isolated and the blood was stored in test tubes coated in heparin. The hearts were rinsed in cold phosphate buffer $\mathrm{pH}$ 8.o, and homogenised in the same buffer. 
The final tissue concentration was $20 \mathrm{mg}$ tissue per $1 \mathrm{ml}$ buffer.

\section{Biochemical analyses}

For the biochemical analyses blood was collected through a glass funnel and placed in appropriate vacutainers coated in heparin. After the collection, the samples remained at room temperature for 15 minutes and then they were centrifuged (15 min x $3000 \mathrm{rpm}$ ) and in the obtained plasma Hcy concentration was analyzed. Following the sacrificing of rats, AChE activity was determined in samples of cardiac tissue homogenate.

\section{Determination of plasma Hcy}

For this process the samples were analyzed using the electrochemiluminescence method (ECL-electrochemiluminescence immunoassay system, ADVIA Centaur XP System, Siemens Healthcare $\mathrm{GmbH}$, Erlangen, Germany). The reference value for Hcy was $<15 \mu \mathrm{mol} / \mathrm{l}$.

\section{Determination of AChE activity}

The specific activity of AChE in samples of cardiac tissue homogenate was determined in vitro by method of Ellman. The method is based on reaction of a colouring reagent $(5,5$-dithio-bis-2-nitrobenzoic acid, DTNB) with the hydrolysis product of thioholine substrate, acetylcholine iodide (AChI), thioholine, to give the compound 5-thio-2-nitro-benzoate-yellow color, whose intensity is proportional to the specific activity of AChE. ${ }^{28}$

\section{Chemicals used}

All chemicals were of p.a. grade quality and were purchased from Sigma Aldrich (Germany).

\section{Statistical analyses}

One-way analysis of variance (ANOVA), followed by Tukey's Post Hoc Test was used for testing statistical significance after testing normality of parameters distribution. Statistical calculation was done using SPSS computer program (SPSS Inc. Chicago, SAD). Values were presented as mean \pm SEM. $\mathrm{P}<0.05$ was considered statistically significant.

\section{RESULTS}

\section{Determination of Hcy}

In the Control group plasma Hcy was $10.4 \pm 0.6$ $\mu \mathrm{mol} / \mathrm{l}$, while in all other plasma samples levels of measured Hcy were higher than $65 \mu \mathrm{mol} / \mathrm{l}$. These results demonstrate moderate hyperhomocysteinemia (30-100 $\mu \mathrm{mol} / \mathrm{l})$.

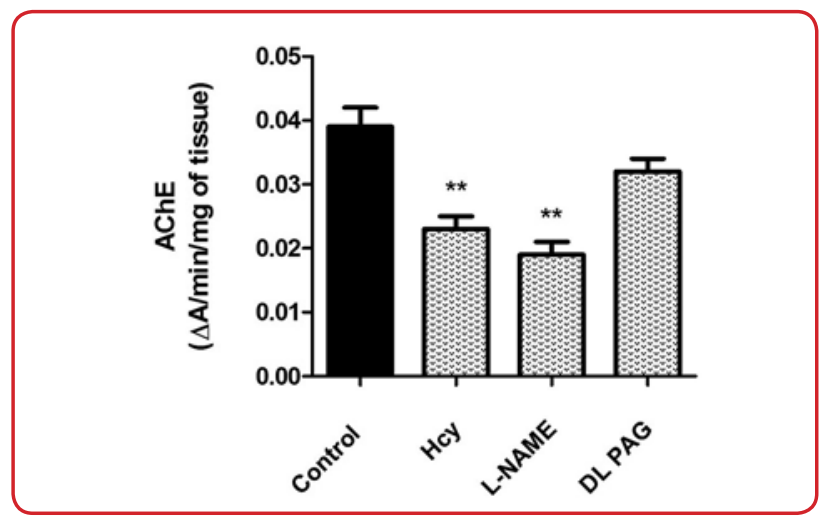

Figure $1 \mathrm{a}$

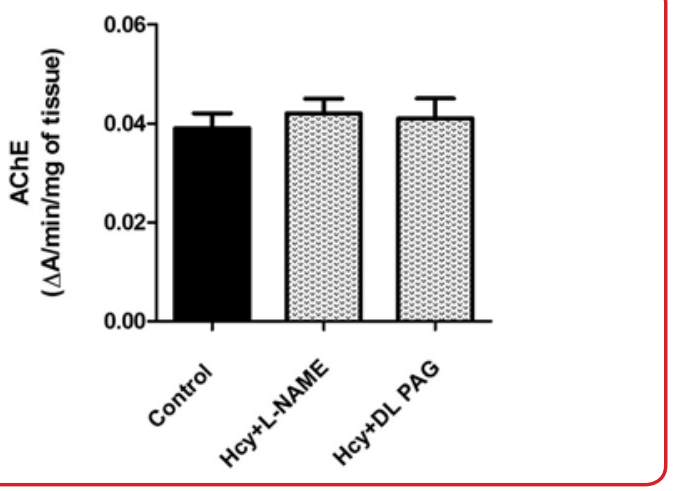

Figure $1 \mathrm{~b}$

Cardiac tissue homogenate AChE activity Administration of Hcy $(0.023 \pm 0.002 \Delta \mathrm{A} /$ $\mathrm{min} / \mathrm{mg}$ of tissue, Figure 1. a) and L-NAME (0.019 $\pm 0.002 \Delta \mathrm{A} / \mathrm{min} / \mathrm{mg}$ of tissue, Figure 1 . a) induced significant decrease in $\mathrm{AChE}$ activity compared with the control group (0.039 \pm 0.003 $\Delta \mathrm{A} / \mathrm{min} / \mathrm{mg}$ of tissue). Administration of DLPAG $(0.041 \pm 0.004 \Delta \mathrm{A} / \mathrm{min} / \mathrm{mg}$ of tissue, Figure 1. a), DL-Hcy+L-NAME (0.042 $\pm 0.003 \Delta \mathrm{A} / \mathrm{min} /$ $\mathrm{mg}$ of tissue, Figure 1. b) and DL-Hcy+DL-PAG (0.041 $\pm 0.004 \Delta \mathrm{A} / \mathrm{min} / \mathrm{mg}$ of tissue, Figure 1. b) did not induce significant changes in AChE activity compared with control condition.

\section{DISCUSSION}

Few studies have proven certain cardioprotective effects of ACh, but only in conditions of hypoxaemia, ischaemia and inflammation..$^{29,30}$ All these conditions are highly correlated with oxidative stress and ROS production. Mentioned studies have shown that these effects are 
achieved by cytokine inhibition ${ }^{30}$, but also by activating muscarinic receptors and NO production. ${ }^{29}$ This could explain the significant reduction of AChE activity in cardiac tissue, observed in this study, in acutely induced hyperhomocysteinaemia as a compensatory mechanism, leading to increase of ACh. Even more prominent decrease of AChE activity occured during application of L-NAME, which is also known as a non-selective muscarinic antagonist. ${ }^{29}$ Contrary to this point of view, it could be assumed that one of potential mechanisms through which Hcy manifests its pro-arrhythmogenic potential ${ }^{31}$ might be decrease of AChE activity, having in mind that AChE is mainly located in region of SA and AV nodles. ${ }^{32}$ Additional investigations are needed to determine whether this is a compensatory mechanism for direct effect of Hcy.

Findings of this study are corroborated by other studies that also showed AChE reduction. ${ }^{15}$ Stefanello and coworkers, investigated the effects of Hcy $(500 \mu \mathrm{M})$ on other cholinesterase involved in ACh degradation, ie BuChE, and found that Hcy strongly inhibited activity of this esterase in rats, as well. ${ }^{15}$ Also, few years later, the same authors examined and compared acute and chronic effects of Hcy on BuChE activity, and these data suggested the inhibitory effects of Hcy also. ${ }^{14}$ The previous study demonstrated that the combination of Hcy and ZnPPR IX has led to increased activity of AChE in relation to the control, suggesting that $\mathrm{CO}$ is potentially very important gaseous molecule for mediation of Hcy-induced effects on cardiac AchE. 33

Finally, the limitation of this study could be that determination of certain gasotransmitters effects was not evaluated directly, but indirectly by inhibition of their production. Data on mRNA or protein levels in the cardiac tissue, as well as cellular data would verify the findings that cardiac $\mathrm{AChE}$ activity is altered by homocysteine level.

\section{CONCLUSION}

It has been concluded that Hcy may alter function of rat heart in part by reduction of AChE activity; however, there are limited supportive data presented in the manuscript. This is an association study where administration of Hcy ip or certain gasotransmitters production inhibi- tion was associated with up-, or downregulation of acetylcholine. This study can contribute to the clarification of these interactions.

\section{CONFLICT OF INTEREST}

None.

\section{ACKNOWLEDGEMENTS}

This work was supported by the Ministry of Education, Science and Technological Development of Republic of Serbia, grant number 175043, and COST action CA16225 entitled "Realizing the therapeutic potential of novel cardioprotective therapies".

\section{AUTHORSHIP STATEMENT}

Marko Djuric: performing of experimental procedures, statistical analysis, interpretation of data, preparation of the manuscript; Slavica Mutavdzin: statistical analysis, interpretation of data, preparation of the manuscript; Dragana Loncar-Stojiljkovic: interpretation of data, analysis of results, preparation of the manuscript; Sanja Kostic: statistical analysis, interpretation of data, preparation of the manuscript; Mirjana Colovic: biochemical analysis; Danijela Krstic: biochemical analysis, interpretation of data; Vladimir Zivkovic: interpretation of data, analysis of results; Vladimir Jakovljevic: interpretation of data, analysis of results; Dragan Djuric: study design, performing of experimental procedures, statistical analysis, interpretation of data, analysis of results, preparation of the manuscript.

\section{REFERENCES}

1. Strain JJ, Dowey L, Ward M, Pentieva K, McNulty H. B-vitamins, homocysteine metabolism and CVD. Proc Nutr Soc 2004;63(4):597-603.

2. Peng HY, Man CF, Xu J, Fan Y. Elevated homocysteine levels and risk of cardiovascular and all-cause mortality: a meta-analysis of prospective studies. J Zhejiang Univ Sci B 2015;16:78-86.

3. Zhu M, Mao M, Lou X. Elevated homocysteine level and prognosis in patients with acute coronary syndrome: a meta-analysis. Biomarkers 2019;24(4):309-16.

4. Cybulska B, Klosiewicz-Latoszek L. Homocysteine - is 
it still an important risk factor for cardiovascular disease? Kardiol Pol 2015;73:1092-6.

5. Omland T, Samuelsson A, Hartford M, Herlitz J, Karlsson T, Christiansen B, et al. Serum homocysteine concentration as an indicator of survival in patients with acute coronary syndromes. Arch Intern Med 2000;160:1834-40.

6. Matetzky S, Freimark D, Ben-Ami S, Goldenberg I, Leor J, Doolman R, et al. Association of elevated homocysteine levels with a higher risk of recurrent coronary events and mortality in patients with acute myocardial infarction. Arch Intern Med 2003;163:1933-7.

7. Facila L, Nuñez JE, G VB, Sanchis J, Bodi V, Chorro FJ, et al. Early determination of homocysteine levels in acute coronary syndromes, is it an independent prognostic factor? Int J Cardiol 2005;100:275-9.

8. Garcia-Pinilla JM, Espinosa-Caliani S, Gómez-Doblas JJ, Jiménez-Navarro M, Gaitán MJ, Muñoz-Morán E, et al. Influence of high homocysteine and low folate plasmatic levels in medium-term prognosis after acute coronary syndromes. Int J Cardiol 2007;118:220-6.

9. Martin-Herrero F, Martín-Moreiras J, Pabón P, Sánchez PL, Morínigo-Muñoz JL, Jimenez-Candil J, et al. Homocysteine and outcome in young patients with acute coronary syndromes. Int J Cardiol 2007;118:1838.

10. Foussas SG, Zairis MN, Makrygiannis SS, Manousakis SJ, Patsourakos NG, Adamopoulou EN, et al. The impact of circulating total homocysteine levels on longterm cardiovascular mortality in patients with acute coronary syndromes. Int J Cardiol 2008; 124:312-8.

11. Van Oijen MG, Claessen BE, Clappers, van Schaik A, Laheij RJ, Jansen JB, et al. Prognostic value of free plasma homocysteine levels in patients hospitalized with acute coronary syndrome. Am J Cardiol 2008; 102:135-9.

12. Gomez M, Valle V, Arós F, Sanz G, Sala J, Fiol M, et al. Oxidized LDL, lipoprotein (a) and other emergent risk factors in acute myocardial infarction (FORTIAM study). Rev Esp Cardiol 2009;62:373-82.

13. Lever M, George PM, Elmslie JL, Atkinson W, Slow S, Molyneux SL, et al. Betaine and secondary events in an acute coronary syndrome cohort. PLoS One 2012;7(5):e37883. doi: 10.1371/journal.pone.0037883.

14. Stefanello FM, Franzon R, Tagliari B, Wannmacher C, Wajner M, Vyse AT. Reduction of butyrylcholinesterase activity in rat serum subjected to hyperhomocysteinemia. Metab Brain Dis 2005;20(2):97-103.

15. Stefanello FM, Zugno AI, Wannmacher CM, Wajner M, Vyse AT. Homocysteine inhibits butyrylcholinesterase activity in rat serum. Metab Brain Dis 2003;18(3):18794.

16. Anglister L, Etlin A, Finkel E, Durrant AR, Lev-Tov A. Cholinesterases in development and disease. Chem Biol Interact 2008;175(1-3):92-100.

17. Prody CA, Zevin-Sonkin D, Gnatt A, Golberg O, Soreq $\mathrm{H}$. Isolation and characterization of full-length cDNA clones coding for cholinesterase from fetal human tissues. Proc Natl Acad Sci USA 1987;84:3555-9.

18. Milatovic D, Dettbarn WD. Modification of acetylcholinesterase during adaptation to chronic, subacute paraoxon application in rat. Toxicol Appl Pharmacol 1996;136:20-8.
19. Massoulié J, Perrier N, Noureddine H, Liang D, Bon S. Old and new questions about cholinesterases. Chem Biol Interact 2008;175(1-3):30-44.

20. Kučera M, Hrabovská A. Cholinergic system of the heart. Ceska Slov Farm 2015;64(6):254-63.

21. Thullbery MD, Cox HD, Schule T, Thompson CM, George KM. Differential localization of acetylcholinsterase in neuronal and non-neuronal cells. J Cell Biochem 2005;96(3): 599-610.

22. Wang R, editor. Signal transduction and the gasotransmitters: NO, CO and H2S in biology and medicine. New Jersey, NJ, USA: Humana Press, 2004.

23. Zivkovic V, Jakovljevic V, Pechanova O, Srejovic I, Joksimovic J, Selakovic D, et al. Effects of DL-homocysteine thiolactone on cardiac contractility, coronary flow, and oxidative stress markers in the isolated rat heart: the role of different gasotransmitters. Biomed Res Int 2013;2013:318471.

24. Aruoma OI, Halliwell B, Laughton MJ, Quinlan GJ, Gutteridge JMC. The mechanism of initiation of lipid peroxidation. Evidence against a requirement for an iron (II)- iron (III) complex. Biochem J 1989;258:61720.

25. Stamler JS, Osborne JA, Jaraki O, Rabbani LE, Mullins $\mathrm{M}$, Singel D, et al. Adverse vascular effects of homocysteine are modulated by endothelium-derived relaxing factor and related oxides of nitrogen. J Clin Invest 1993;91:308-18.

26. Xu S, Liu Z, Liu P. Targeting hydrogen sulfide as a promising therapeutic strategy for atherosclerosis. Int J Cardiol 2014;172:313-7.

27. Kabil O, Motl N, Banerjee R. H2S and its role in redox signaling. Biochim Biophys Acta 2014;1844:1355-66.

28. Ellman GL, Courtney KD, Andres V Jr, Featherstone RM. A new and rapid colorimetric determination of acetylcholinesterase activity. Biochem Pharmacol 1961;7:88-95.

29. Liu H, McPherson B, Zhu X, Da Costa M, Jeevanandam $\mathrm{V}$, Yao Z. Role of nitric oxide and protein kinase $\mathrm{C}$ in Ach-induced cardioprotection. Am J Physiol Heart Circ Physiol 2001;281(1):H191-7.

30. Yuan X, Teng X, Wang Y, Yao Y. Recipient treatment with acetylcholinesterase inhibitor donepezil attenuates primary graft failure in rats through inhibiting post-transplantational donor heart ischaemia/reperfusion injury. Eur J Cardiothorac Surg 2018;53(2):4008.

31. Soni CV, Tyagi SC, Todnem ND, Givvimani S, Pushpakumar SB, Villafane J, et al. Hyperhomocysteinemia alters sinoatrial and atrioventricular nodal function: role of magnesium in attenuating these effects. Cell Biochem Biophys 2016;74(1):59-65.

32. Rysevaite K, Saburkina I, Pauziene N, Noujaim SF, Jalife J, Pauza DH. Morphologic pattern of the intrinsic ganglionated nerve plexus in mouse heart. Heart Rhythm 2011;8(3):448-54.

33. Hadžibegović A, Ćuk J, Krstić D, Đurić D. The effects of homocysteine and a carbon monoxide synthesis inhibitor, applied separately and simultaneously, on acetylcholinesterase activity in the rat heart tissue. Med Podml 2016,67(4):30-5. Serbian. 